\title{
EXPECTATIVAS DE FAMILIARES DE CLIENTES EM UTI SOBRE 0 ATENDIMENTO EM SAÚDE: ESTUDO SOCIOPOÉTICO
}

\author{
Expectations of family members of clients in the ICU on health \\ care: Socio-poetic Study
}

\author{
Expectativas de familiares de clientes en uti sobre el cuidado \\ de la salud: estudo sociopoético.
}

Iraci dos Santos ${ }^{2}$

\begin{abstract}
RESUMO
Considerando a política de humanização no atendimento de saúde, tem-se como o problema de pesquisa: quais são as expectativas dos familiares de clientes internados em Unidade de Terapia Intensiva (UTI) quanto à humanização no atendimento pela enfermagem atuante neste setor? Objetivo: analisar a dimensão imaginativa dos familiares de clientes hospitalizados em UTI, identificando suas expectativas sobre o atendimento de suas necessidades humanas pela equipe de enfermagem. Pesquisa sociopoética realizada em 2008 em um Hospital do Rio de Janeiro, Brasil. Grupo Pesquisador: 11 familiares. Resultados com as categorias analíticas: Superando sentimentos de ansiedade; Refletindo sobre as informações de saúde e Fontes de superação da internação do familiar em UTI. Concluiu-se que os familiares expressaram expectativas positivas em relação à internação do cliente, por meio do acolhimento e das informações recebidas. Como contribuição do estudo, acredita-se que, com a orientação e o acolhimento da enfermagem, eles poderão ultrapassar suas expectativas, possibilitando seu crescimento individual e maior aquisição de habilidades em qualidades humanas.
\end{abstract}

Palavras-chave: Enfermagem. Família. Humanização da Assistência

\begin{abstract}
Considering the policy of humanization in health care, there is a problem of research, which are the expectations of family members of clients in the ICU on health care regarding the humanization of nursing care by acting in this sector.

Objective: the imaginative dimension of family members of hospitalized patients in ICU, identifying their expectations about the care of human needs by the nursing staff. It is a socio-poetic research accomplished in 2008, in a Hospital of Rio de JaneiroBrazil. Researcher Group: 11 relatives. The results with the analytical categories: Overcoming feelings of anxiety; Reflecting on the health information and overcoming sources concerning the hospitalization of a family member in ICU.

It was concluded that family members expressed positive expectations regarding the patient admission through the host and the information received. As a contribution to the study, it is believed that with the nursing guidance and care, they can exceed their expectations enabling individual growth and increase acquisition of skills in human qualities.
\end{abstract}

Keywords: Nursing. Family. Humanization of assistance.

\section{Resumen}

Considerando la política de humanización en la asistencia de salud, se presenta el problema de la investigación: ¿cuáles son las expectativas de los familiares de los enfermos internados en Unidad de Terapia Intensiva (UTI) en lo relacionado con la humanización en el cuidado brindado por el equipo de enfermería actuante en este setor? Objetivo: analizar la dimensión imaginativa de los familiares de clientes hospitalizados en la UTI, identificando las expectativas que tienen de la atención de sus necesidades humanas por el equipo de enfermería. Investigación sociopoética realizada en 2008, en un Hospital de Río de Janeiro-Brasil. Grupo investigador 11 familiares. Resultados con las categorías analíticas: Superando sentimientos de ansiedad; Reflexiones sobre la información de salud y Fuentes de superación de la internación del familiar en la UTI. Se concluyó que los familiares expresaron expectativas positivas en relación a la internación del cliente, a través del acogimiento ofrecido por el equipo de enfermería y de las informaciones recibidas. Como contribución del estudio, se cree que, con la orientación y el acogimiento de la enfermería, los familiares podrán ultrapasar sus expectativas haciendo posible su crecimiento individual y el mayor desarrollo de las habilidades en el ambito de las cualidades humanas.

Palabras clave: Enfermería. Familia. Humanización de la asistencia.

\footnotetext{
Enfermeira. Mestranda de Enfermagem da Universidade do Estado do Rio de Janeiro. Enfermeira Especialista em Enfermagem Clínica e Cirúrgica. Enfermeira Intensivista, Professora Auxiliar de Ensino Superior no Centro Universitário Celso Lisboa. Endereço: Av. Joaquim Magalhães, 180 BL 09 Apt 302 Senador Vasconcelos Rio de Janeiro CEP: 23012-120. Brasil. E-mail: silva415@terra.com.br

, '2Enfermeira. Doutora em Enfermagem. Professora Titular da Universidade do Estado do Rio de Janeiro. Professora do Programa de Pós-Graduação em Enfermagem da Faculdade de Enfermagem/UERJ. Brasil. E-mail: iraci.s@terra.com.br
} 


\section{INTRODUÇ̃̃O}

A Política Pública de Saúde "Humaniza SUS"1 constitui uma demanda atual e crescente no contexto brasileiro, pois emerge das queixas dos usuários sobre a qualidade do atendimento dos serviços de saúde. Tal situação é corroborada por afirmações ${ }^{2-3}$ sobre a crise de humanismo enfrentada nesses serviços, atingindo importantes dimensões da vida de clientes, seus familiares e, também, profissionais da área de saúde.

A humanização do atendimento em saúde depende das condições de trabalho do profissional dessa área, bem como de sua competência e habilidades técnicas, inclusive no âmbito das relações humanas. Portanto, a humanização no cuidar em enfermagem é indispensável para estabelecer a interação e o relacionamento com os usuários dos serviços de saúde, incluindo os seus familiares e os profissionais de saúde.

Neste trabalho, destaca-se a preocupação de estudiosos e pesquisadores, durante 0 artigo mencionado, em incluir os familiares da pessoa internada em Unidade de Terapia Intensiva (UTI) como cliente da equipe de saúde. Essa consideração vai além da esperada contribuição da família na recuperação do indivíduo hospitalizado, pois a família tem sido vista principalmente pela enfermagem como aliada no processo saúde-doença familial, e, em determinadas situações, os profissionais precisam oferecer-lhes condições de manter 0 núcleo familiar saudável, cuidando da pessoa sem que haja agravo à saúde desta e da família como um todo.

Para isso, torna-se necessário reconhecer que os visitantes (familiares) de clientes críticos também necessitam de cuidados de saúde e enfermagem. ${ }^{3}$ As considerações acerca deste assunto referem-se ao fato de que, ao ajudar na recuperação de seu familiar hospitalizado e/ou contribuir com uma visita ou solicitação de informações, a pessoa sente-se envolvida, preocupada e muitas vezes ansiosa e estressada diante das notícias sobre o estado de saúde daquele que se encontra afastado do seu ambiente familiar, de trabalho e social.

A experiência no cotidiano do trabalho mostra a ocorrência do exposto, podendo-se dizer que a humanização deve ser resgatada, pois é um direito do ser humano ter sua dignidade mantida, respeitando-se suas necessidades, valores, crenças, princípios éticos e morais. ${ }^{4}$

Nesse contexto, a família promove sua própria saúde, a partir dos primeiros cuidados no ambiente familiar, desenvolvendo as potencialidades de seus membros para se autocuidar. ${ }^{5}$ Silva, Porto, Figueiredo $0^{6}$ apoiam-se em alguns teóricos que pensam o cuidado como uma peculiaridade do humano e condição primeira de sua existência.

Portanto, sendo a família um suporte para a situação vivenciada pela pessoa adoecida, adquire o direito de ter 0 apoio da equipe de enfermagem para atender suas necessidades físicas, emocionais, intelectuais e espirituais. Concorda-se, nesse caso, que é praticamente impossível assistir o indivíduo (doente ou sadio) de forma completa quando se desconsidera sua família (consanguínea ou social), pois vários estudos demonstram que ela pode ser entendida tanto como fonte de saúde como de doença para seus membros. ${ }^{5-7}$

\section{Amplitude do problema}

Este trabalho é um recorte do Relatório Parcial de Dissertação de Mestrado ${ }^{3}$ desenvolvida no Programa de PósGraduação da Faculdade de Enfermagem da Universidade do Estado do Rio de Janeiro. Nessa dissertação foram abordados o acolhimento e as informaç̃oes prestadas sobre a saúde do cliente internado em UTI, aos seus familiares, pela enfermagem do campo de pesquisa. Tal objeto de estudo foi delimitado considerando-se sua relevância diante dos resultados obtidos por meio de revisão sistemática, rastreando-se bases de dados eletrônicas, realizada no estudo da disser tação mencionada anteriormente.

No levantamento do material já publicado, observamos poucos trabalhos com abordagem sobre necessidades humanas dos familiares. Assim, analisando mais atentamente essas necessidades, concluiu-se que os familiares de clientes de UTI se ressentem da falta de acolhimento e de informações sobre saúde. ${ }^{8}$

Sendo assim, tendo como relevância os poucos trabalhos encontrados durante a realização do rastreamento em bases eletrônicas, o presente estudo se justifica pela conclusão da dissertação em questão de que os familiares demonstram seus sentimentos e a necessidade de relatá-los.

Diante do exposto, apresenta-se o problema de pesquisa: quais são as expectativas dos familiares de clientes internados em UTI quanto à humanização do seu atendimento por profissionais de enfermagem atuantes neste setor? Para respondê-lo, formulou-se o objetivo: analisar a dimensão imaginativa dos familiares de clientes hospitalizados em UTI, identificando suas expectativas sobre 0 atendimento de suas necessidades humanas pela equipe de saúde.

\section{METODOLOGIA}

Trata-se de um pesquisa descritiva, com o referencial teórico-metodológico sociopoético, que privilegia a participação efetiva dos sujeitos da pesquisa, oferecendo-lhes a oportunidade de expressar, através do imaginário, seus sentimentos, necessidades e desejos. ${ }^{9} 0$ Grupo Pesquisador (GP), que é o dispositivo analítico da sociopoética, foi implementado em seis fases, de acordo com os seguintes princípios filosóficos ${ }^{9-10}$ :

1- Os sujeitos da pesquisa são considerados copesquisadores. Eles participam desde a fase da negociação, 
para produzir os dados, até a socialização dos resultados, pois os temas norteadores da investigação não podem ser impostos, mas surgir do diálogo entre os pesquisadores ${ }^{9-12}$ o $\mathrm{GP}$.

Após a aprovação do Comitê de Ética do Hospital Universitário Pedro Ernesto, da Universidade do Estado do Rio de Janeiro- Brasil, Protocolo n. 1954, realizaram-se as Oficinas Sociopoéticas, no período de janeiro a abril de 2008. Neste trabalho, foi formado um Grupo Pesquisador composto por 11 familiares de clientes internados na UTI, independente do grau de parentesco, mediante a um convite prévio escrito e verbal dos 22 clientes que estavam internados, os quais aceitaram participar da investigação depois de informados sobre sua temática, objetivos, vantagens e riscos, assinando o Termo de Consentimento Livre e Esclarecido.

0 campo da pesquisa foi um Hospital de Saúde Particular, situado no Rio de Janeiro, ressaltando-se que o ambiente para realização destas oficinas foi totalmente preparado com a sala fechada, sem contato com o meio externo, e música ambiente (instrumental) que só cessava ao término da oficina. Assim, os membros do GP puderam incentivar seu imaginário para descrever as imagens expressas nas suas produções artísticas. Foram realizadas 10 reuniões, com duração de duas horas, nas quais, inicialmente, os membros do GP discutiram sobre o seguinte Tema Orientador apresentado pela pesquisadora: Se suas expectativas quanto ao seu atendimento na UTI fossem os lugares geomíticos Terra, Poço, Túnel, Caminho, Labirinto, Gruta e Estrada... como seria?

2-Aimportância do corpo como fonte de conhecimento. Com a sociopoética, não se pesquisa utilizando somente a racionalidade, mas integrando-a ao sentimento, à emoção e à intuição, visto que o corpo somente pensa quando integrado com o espirito e todas as formas de pensar., ${ }^{9}, 12$ Esse princípio se relaciona ao que a sociopoética traz em seu discurso, que a ciência deve estudar as energias impressas nos corpos dos sujeitos participantes da pesquisa. Com esse método, pretende-se, no desvelamento e na análise do Grupo Pesquisador, alcançar a expressão dessas energias as quais nos permite entender as experiências de vida das pessoas e seus saberes.

0 processo de coleta de dados é caracterizado e denominado como produção de dados, através das oficinas sociopoéticas mencionadas anteriormente. Em cada oficina, para pesquisar com todo o corpo foi utilizada a Dinâmica de Sensibilidade "Vivência de Lugares Geomíticos", precedida de um relaxamento, considerando que na investigação através do imaginário são integradas as diversas formas de pensar para facilitar a expressão

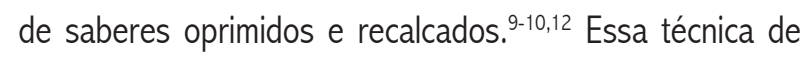
investigação foi aplicada mediante um formulário próprio contendo os lugares geomíticos, os quais foram associados pelos membros do GP, ao Tema Orientador apresentado.

3- Importância da criatividade de tipo artística, no aprender, no conhecer e no pesquisar. Recorda-se, ainda, que o imaginário é um dos pilares do método sociopoético, por ser considerado como o inconsciente, que carrega as nossas aceitações e cumplicidades com os poderes hegemônicos, as repressões instituídas, as ideologias dominantes. ${ }^{12}$

4- A importância do sentido espiritual, humano, das formas e dos conteúdos do saber, considerando o processo de investigação como um pensar junto de facilitadores, independente da qualificação profissional e o grupo pesquisador, com aprendizagem mútua pautada na teorização da pedagogia do oprimido. ${ }^{9-12}$

5- Valorizar os conceitos produzidos pelas culturas dominadas e de resistência. A produção de dados, deste trabalho, aconteceu na Oficina Sociopoética onde o GP expressou seu conhecimento, mediado pelo imaginário, sobre o tema orientador escolhido.

Os dados produzidos foram submetidos à análise categorial simples,juntoao GP, visto queasociopoéticatem como objetivoadescoberta daestrutura do pensamento do grupo, na sua heterogeneidade, enãoa análise do discurso individual de cada componente do grupo. Ofacilitador (pesquisador institucional) não traça o caminho da análise, a fim de permitir que o GP expresse suas próprias modalidades de reflexão e organizaçãodos dados..$^{12}$

Como a sociopoética tem como objetivo a descoberta da estrutura do grupo na sua heterogeneidade, e não a análise individual, a análise dos dados produzidos tem de ser em grupo, 0 que caracteriza a fase de Contra-análise, procedente da Análise Institucional. 0 facilitador tem o cuidado de não traçar o caminho da análise, permitindo, assim, que o grupo pesquisador expresse suas próprias modalidades de reflexão e organização dos dados ${ }^{10}$. Essa etapa do método representa a sexta fase deste dispositivo analítico do método, caracterizando a simultaneidade da aplicação dos seus princípios filosóficos e fundamentos teóricos com a preconizada socialização dos saberes ${ }^{13-14} \mathrm{e}$ avaliação de todo o processo de pesquisa. ${ }^{9}$ Transforma-se o produto da atividade em objeto de conhecimento, baseando-se nos seguintes estudos sociopoéticos:

- Classificatório - esse estudo destaca as oposições, dicotomias entre os dados produzidos;

- Transversal-esse estudo revela as ligações entre coisas aparentemente diferentes que surgem na produção das oficinas de pesquisa;

- Surreal - estudo característico da aplicação da Vivência de Lugares Geomíticos, no qual temas idênticos surgem em diferentes lugares geomíticos; 
- Filosófico - análise a partir das referências teóricas, cultura, crenças surgidas com os dados produzidos.

Neste recorte de dissertação, descrevem-se nos resultados apenas os estudos transversal e surreal. Destaca-se que o método sociopoético utiliza a análise por categorização.

\section{RESULTADOS E DISCUSSÃO}

\section{Estudos Sociopoético:Transversal e Surreal}

A análise das criações do GP privilegia um momento em que se permite transformar o produto da atividade dos membros do grupo em objeto de conhecimento, sem excluir a essência da sua dinâmica. Assim, o produto não se torna um objeto morto, preparado para análise, um mero símbolo sem vida, separado, congelado; ele mantém o seu devir, suas contradições, sua clareza e sua escuridão. ${ }^{11-12}$

Portanto, a descrição dos resultados da produção de dados na Oficina Sociopoética revela um produto desta atividade, que aparece como uma mistura de coisas as quais se pode colocar em palavras claras e outras que não se pode enunciar. ${ }^{11-12}$

Foram delimitados, por meio dos dados produzidos, os temas segurança, insegurança, esperança, crescimento, reflexão e dificuldade de entendimento, que expressam a dimensão imaginativa do GP ao associar a pergunta orientadora da pesquisa aos lugares geomíticos: terra, poço, túnel, labirinto, gruta, caminho e estrada. Esses temas sintetizam o total de 46 falas/discursos do GP, caracterizando a estrutura do pensamento grupal dos sujeitos da pesquisa. A partir dessa delimitação, foram elaboradas as categorias temáticas (união de temas mediante os estudos sociopoéticos) e realizados os estudos sociopoéticos transversal e surreal.

\section{Superando sentimentos de ansiedade}

Descreve-se o estudo transversal realizado desde a delimitação da categoria composta pela predominância do tema Insegurança (10), imaginada nos lugares geomíticos terra, poço, túnel e labirinto, e do tema Segurança (9), delimitado nos lugares terra, poço, túnel, gruta e caminho. Refletindo-se sobre a estrutura de três desses lugares (poço, túnel e labirinto), intui-se que o surgimento da insegurança deve-se ao fato de 0 grupo pesquisador não conseguir visualizar uma saída nesses lugares, para recuperação do seu familiar internado na UTI.

A dimensão imaginativa expressa no discurso do grupo revela sua dificuldade em pensar possibilidades de cura diante da situação de saúde enfrentada por seu familiar, que dá origem aos sentimentos de medo e outras emoções a serem controladas.
Isto porque a hospitalização de um familiar em UTI geralmente ocorre de forma inadvertida, restando pouco tempo para o ajustamento familiar. Depreende-se de tal fato que essa situação é estressante para os familiares, fazendo-os sentir-se desorganizados, desamparados e com dificuldades para se mobilizar, diante de suas variadas necessidades a serem atendidas. $^{13}$

$\mathrm{Na}$ expectativa de encontrar uma saída para resolver sua dificuldade para visualizar a recuperação do seu familiar internado, o GP imagina que suas necessidades podem ser atendidas se a equipe de enfermagem puder relacionar os fatores sociais, econômicos, culturais, para interagir com as situações por ele enfrentadas visando à integridade familiar. ${ }^{14}$

Após essa interação dos familiares com a equipe de enfermagem através do acolhimento e as informações recebidas, a insegurança foi transformada em segurança, visto ter o GP imaginado a gruta como um "porto seguro" onde o acolhimento e as informações recebidas the fornecem a proteção esperada, qual seja, um escudo para amortizar sua ansiedade.

Este pensamento, experimentação/interpretação dos dados produzidos, deve-se ao fato de que os dois temas apareceram em lugares idênticos, exceto na gruta (onde me esconder... para sobreviver diante da incerteza?) e no caminho (lugar para onde fugir...) que definiram o tema segurança. Observa-se, nesse caso, que, na dimensão imaginativa, o GP tem a expectativa de escapar das tormentas diante das possibilidades de morte, "assegurando-se" das informações sobre a saúde de seu familiar.

\section{Refletindo sobre as informações sobre saúde}

Esta categoria é formada pelos temas Reflexão (1), que surgiu no lugar geomítico labirinto, e Dificuldade de entendimento (4), o qual aparece nos lugares poço, labirinto e caminho. As falas do GP que permitiram a delimitação desses temas expressam que os familiares sentem a internação do cliente na UTI como um sinal de morte iminente, talvez devido às suas experiências prévias ou as de pessoas conhecidas.

Ressalta-se, no setor citado, a existência de estímulos provocadores da ansiedade gerada pela preocupação com a tecnologia do cuidado à saúde, mediante uma variedade de equipamentos e aparelhos. Tais estímulos parecem preocupar mais os familiares do que a própria ameaça à vida da pessoa adoecida e hospitalizada. Outro fator estressante é o despreparo desses visitantes para adentrar no estranho ambiente/ lugar que é a UTI.

Esse setor lhes parece, portanto, um território surreal, formado por um poço, labirinto e um caminho. São lugares 
temidos e, em sua imaginação, tornam-se de difícil entendimento. É necessário refletir para encontrar a saída, pois o poço tem um fundo que pode ser a fonte do saber.

0 caminho, se associado a um novo viver, pode ser orientado pelo "mapa/informações sobre a saúde do cliente", 0 qual o caminhante seguirá para encontrar a saída do labirinto (enlouquecimento da dor, desespero devido ao que lhe é desconhecido). Sua expectativa, então, é a de sair para encontrar o refúgio/esperança na possibilidade de recuperação do seu familiar.

Imaginar a UTI/labirinto é pensar no desafio de refletir sobre a vida, seu sentido, o significado do viver/morrer. 0 labirinto é desafio constante, necessário para o autoconhecimento, descoberta de nosso potencial de reação, de resistência humana. Refletir sobre o encontro com a UTI, um lugar surreal, desconhecido, faz com que os familiares vivenciem dificuldades de entendimento.

Este lugar gera necessidades de saber tudo o que está ocorrendo para se tornar independente do julgamento dos profissionais de saúde. ${ }^{14}$ Assim, diante da hospitalização de um ente querido na UTI, os familiares geralmente "adoecem" junto com ele.

Este fato provoca uma desestruturação em níveis biopsicossocial-espiritual, inicialmente marcado por um nível de ansiedade advinda do risco de perda, da longa espera pelo horário de visita, por um diagnóstico, por uma solução, por informação e, ainda, por uma palavra de esperança. ${ }^{15}$

Enfim, essa dificuldade de entendimento perpassa por esse mundo desconhecido que é a UTI, com seus equipamentos, ambiente e linguagem técnica-científica, que muitas vezes causam mais estranhamento aos familiares do que a própria trajetória da doença e a internação em si.

Desse modo, as informações sobre a saúde do cliente em UTI veiculadas por meio de palavras nunca escutadas e/ou faladas, junto aos fatores estressantes, afetam a percepção da realidade dos familiares, ficando difícil o seu entendimento sobre essa situação.

0 Grupo Pesquisador também demonstra que, em virtude da dificuldade de entendimento acima citada, ele consegue refletir sobre a vida e sobre tudo que está lhe acontecendo. Por meio da reflexão, os familiares admitem os sentimentos da família e reconhecem a complexidade do problema vivenciado, enquanto enfatizam a responsabilidade de cada pessoa por seus próprios sentimentos, ações e decisões. ${ }^{16}$

Desse modo, a dificuldade de entendimento revelada no lugar geomítico labirinto é a afirmação da necessidade que se tem de um momento para pensar, refletir para descobrir o 0 real sentido da humanização do cuidar em saúde abrange a capacidade de a pessoa refletir sobre o cuidado como força de vida que dinamiza o viver humano. ${ }^{18}$

\section{CONCLUSÃO}

Conclui-se que, utilizando o referencial teórico-metodológico dasociopoética, foi possível responder ao problemade pesquisaealcançar o objetivo formulado. Através da Vivência de Lugares Geomíticos, os familiares dos clientes internados emUTl expressaram seu imaginário relatando a sua experiência de conviver com essa situação, revelandose, desse modo, suas expectativas quanto ao seu atendimento/ acolhimento na unidade citada.

As categorias "Superandosentimentos de ansiedade", "Refletir sobre as informações sobre saúde" e "Fontes para superação da internação dofamiliarem UT",'analisadas medianteos estudostransversal e surreal, revelaram ligações existentes entre coisas aparentemente diferentes expressas na dimensão imaginativa dos sujeitos de pesquisa.

Em resposta ao problema formulado, conclui-se que os familiares expressaram expectativas positivas em relação à internação do cliente. Eles imaginam que, através do acolhimento eas informações sobre a saúde do mesmo, poderão definir melhor seus sentimentos, direcionando seus objetivos paraaguardar aesperadarecuperação.

Tais expectativas, antes desfavoráveis devido a anteriores experiênciasnegativas ou desconhedidas, transformam suainsegurança em segurança no atendimento da equipe de enfermagem, conforme descritona categoria "Superando sentimentos de ansiedade".

Assim, a necessidade, sentida pelo familiar, de enfrentar seus confitos devido ao estranhamento do lugar complexo queéaUTleàsua incapacidade de nele sentir-se àvontade sem, entretanto, não conseguir se afastar do seu ente querido, demarca o conformismo de um viver social, de um gregarismo, percebido ounãopelo ser humano. Isto porque asociedade exige sempreque os seus membros ajam como sefossem dotados de um único interesse. Nesse caso, sejam eles saudáveis ou não, o que interessaéa sobrevivência eintegração dafamilia., ${ }^{7} 17$

Asfalas do GP conduzem à crença de que, com o crescimento mental, espiritual, possibilitado por experiências vivenciadas durantea visita ao seu familiar, quanto ao atendimento humanizado da enfermagem, eletem expectativas de visualizar a saída/ recuperação do cliente e encontrar um modo de lidar com a internação emUTI. Desse modo, ao vivenciar esselugar temido, oGP tem expectativas de encontrar a terra/ familia das suas rázes, origem; a terra na qual se plantaráa esperança/vida. Conclui-se, portanto, que afamiliatem expectativas de encontrar um profissional que he ajude a compreender os momentos dificeis, que demandam ações, sentimentos epensamentos, nem sempre positivos. Refletindo sobre o conhecimento produzido nesta pesquisa, vale destacar como contribuição do estudo a crença de que, com a orientação, a ajuda e o acolhimento da enfermagem, os familiares de 
clientes poderão ultrapassar suas expectativas possibilitando seu crescimento individual emaior aquisição de habilidades em qualidades humanas.

\section{REFERÊNCIAS}

1- Ministério da Saúde (BR). Secretaria de Assistência à Saúde. Programa Nacional de Humanização da Assistência Hospitalar. Brasília (DF); 2001.

2- Backes DS, Lunardi Filho, WD, Lunardi, VL. Humanização no ambiente hospitalar à luz da política de humanização da assistência à saúde. Enferm Atual 2005 jul/ago; 4 (4): 227-31.

3- Silva FS. Dimensão imaginativa dos familiares de clientes internados em unidade de terapia intensiva: necessidades de acolhimento e informações sobre saúde. [dissertação de mestrado]. Rio de Janeiro (RJ): Universidade do Estado do Rio de Janeiro/ UERJ; 2008.

4- Leite RS, Nunes CV, Beltrame I. Humanização hospitalar: análise da literatura sobre a atuação da enfermagem [on-line]. [citado maio 2005]. Disponível em: http://www.sobragen.org.br/publi/publi5.pdf

5- Elsen I, Patrício ZM. Assistência à criança hospitalizada: tipos de abordagens e sua implicação para a enfermagem. In: Schmitz EMR. A enfermagem em pediatria e puericultura. Rio de Janeiro (RJ): Atheneu; 1986.

6- Silva RCL, Porto IS, Figueiredo NMA. Reflexões acerca da assistência de enfermagem e o discurso de humanização em terapia intensiva. Esc Anna Nery Rev Enferm 2008 mar; 12(1): 156-59.

7- Elsen I. Um marco conceitual para o trabalho com famílias. In: Stamm M, Mioto RCT. Família e cuidado: uma leitura além do óbvio. Cienc\&Cuid Saude 2002 jul/dez; 2 (2):161-68.

8- Torrents R, Oliva TE, Saucedo FMJ, Surroca SL, Jover SC. Impacto de los familiares del paciente crítico. Ante una acogida protocolizada. Rev Enferm Intensiva 2003 abr/jun;14 (2): 49-60.

9-Schittini APP. A equipe de enfermagem e a orientação à família do paciente internado em UTI. [dissertação de mestrado]. Curitiba (PR): Universidade Federal do Paraná/ UFPR; 1995.

10-Santos I, Gauthier J, Figueiredo NMA, Petit SH. Prática de pesquisa nas ciências humanas e sociais: abordagem sociopoética. São Paulo (SP): Atheneu; 2005.

11-Brandão ES. 0 cuidar de enfermagem ao cliente com afecção cutânea: paradigma sociopoético. [dissertação de mestrado]. Rio de Janeiro (RJ): Universidade do Estado do Rio de Janeiro/ UERJ; 2002.

12-Freire P. Pedagogia do oprimido. $36^{\mathrm{a}}$ ed. Rio de Janeiro(RJ): Paz e Terra; 2006
13-Freitas KS, Kimura M, Ferreira KASL. Necessidades de familiares de pacientes em unidade de terapia intensiva: análise comparativa entre hospital público e privado. Rev Latino-am Enfermagem 2007 jan/fev; 15 (1): 84-92.

14-Angelo M, Bousso RS. Fundamentos da assistência à família em saúde. Manual de enfermagem [on-line]. [citado jun 2008]. Disponível em: http://www.ids-saude.org.br/enfermagem.

15-Junior MMM, Faria MDG. Humanização na UTI Pediátrica. In:Magalhães AMPB. Humanização em cuidados intensivos - AMIB. Rio de Janeiro(RJ): Revinter; 2003.

16-Hudak CM, Gallo BM. Cuidados intensivos de enfermagem: uma abordagem holística. $6^{\text {a }}$ ed. Rio de Janeiro(RJ): Guanabara Koogan; 1997.

17-Angelo M. Abrir- se para a família: superando desafios. Fam Saude Desenvolv 1999 jan/dez;1 (1,2): 7-14.

19-Martins JJ, Backes DS, Cardoso RS, Erdmann AL, Albuquerque GL. Resignificando la humanización desde el cuidado en el curso de vivir humano. Rev Enferm UERJ 2008 abr/jun; 16 (2): 276-81 